\title{
MEWUJUDKAN GENERASI MUDA YANG UNGGUL DI ERA GLOBALISASI DENGAN BERBEKAL ILMU WIRAUSAHA YANG KREATIF, INOVATIF DAN DIFERENSIATIF PADA REMAJA MASJID AL HIKMAH RENI JAYA PAMULANG TANGERANG SELATAN
}

\author{
${ }^{1}$ Aidil Amin Effendy, ${ }^{2}$ Mahnun Mas'adi, ${ }^{3}$ Widhi Wicaksono, ${ }^{4}$ Ahmad \\ Nurhadi, ${ }^{5}$ Heri Murtiyoko \\ Dosen Fakultas Ekonomi Universitas Pamulang \\ Email : $\underline{\text { aidilamineffendy@gmail.com }}$
}

\begin{abstract}
ABSTRAK
Remaja sebagai Generasi muda saat ini lebih banyak yang menginginkan mendapatkan pekerjaan dibandingkan berwirausaha, hal ini didukung berbagai data dan penelitian dimana kurang minatnya remaja untuk berwirausaha, maka Tujuan dari Kegiatan Pengabdian kepada Masyarakat adalah dapat mempersiapkan remaja sebagai generasi muda yang berkompeten dan mempunyai daya saing tinggi di masyarakat untuk menjadi seorang wirausahawan yang tidak hanya dapat mengurangi jumlah pengangguran tetapi juga secara jangka panjang dapat berkontribusi terhadap negara dalam pembangunan perekonomian nasional.

Metode yang digunakan pada Pengabdian masyarakat ini berupa penyampaian materi secara verbal mengenai ilmu kewirausahaan dan pelajaraan dari kisah Sukses dalam berwirausaha, bimbingan dalam menjalankan bisnis sampai remaja masjid benar-benar dapat memulai dan menjalankan usahanya dan Praktek dan simulasi cara dagang dan bahasa dalam menjual produk, sehingga pihak remaja masjid dapat ilmu dan praktek cara berwirausaha yang baik dan benar.

Hasil pengabdian masyarakat yang diperoleh adalah bertambahnya keilmuan remaja masjid Al Hikmah mengenai kewirausahaan, adanya konsultasi dan bimbingan usaha oleh Tim Dosen Unpam dan Kartu atau form evaluasi bisnis, dimana remaja masjid diberikan kartu atau form evaluasi bisnis agar mereka dapat mengetahui praktek langsung dalam berwirausaha sehingga pihak remaja masjid dalam memiliki usaha masing-masing yang dapat berkembang, mampu bersaing dan unggul di era Globalisasi.
\end{abstract}

Kata Kunci : Remaja Masjid, Generasi Muda, Ilmu Pengetahuan,Wirausaha 


\section{PENDAHULUAN}

Masjid tidak hanya diperuntukkan pelaksanaan ibadah sholat 5 waktu, namun perlu juga kegiatan keagamaan lainnya atau pembelajaran bagi para jamaah terutama remaja masjid yang ada di dalamnya. Saat seorang remaja dapat memanfaatkan waktunya dengan baik dan memiliki ide dalam mendirikan usaha, maka mereka akan lebih termotivasi untuk mengembangkannya. Karena remaja merupakan generasi muda harapan bangsa yang harus berperan lebih dalam mengembangkan usaha di tengah-tengah masyarakat.

Seluruh elemen masyarakat harus mampu menciptakan generasi muda Islam berkarakter santun dan cerdas, namun generasi muda saat ini lebih banyak yang menginginkan mendapatkan pekerjaan dibandingkan berwirausaha, seperti dalam Data BPS Kota Tangerang Selatan, mengenai data Penduduk yang bekerja pada umur 15 Tahun Ke Atas, menurut kelompok umur dan jenis kelamin di kota Tangerang Selatan, diperoleh data pada kelompok umur 25-54 lebih banyak penduduk yang bekerja sebanyak 495.539 penduduk dibandingkan kelompok umur 15-24 sebanyak 96.482 penduduk dan 55 tahun ke atas sebanyak 68.224 penduduk.

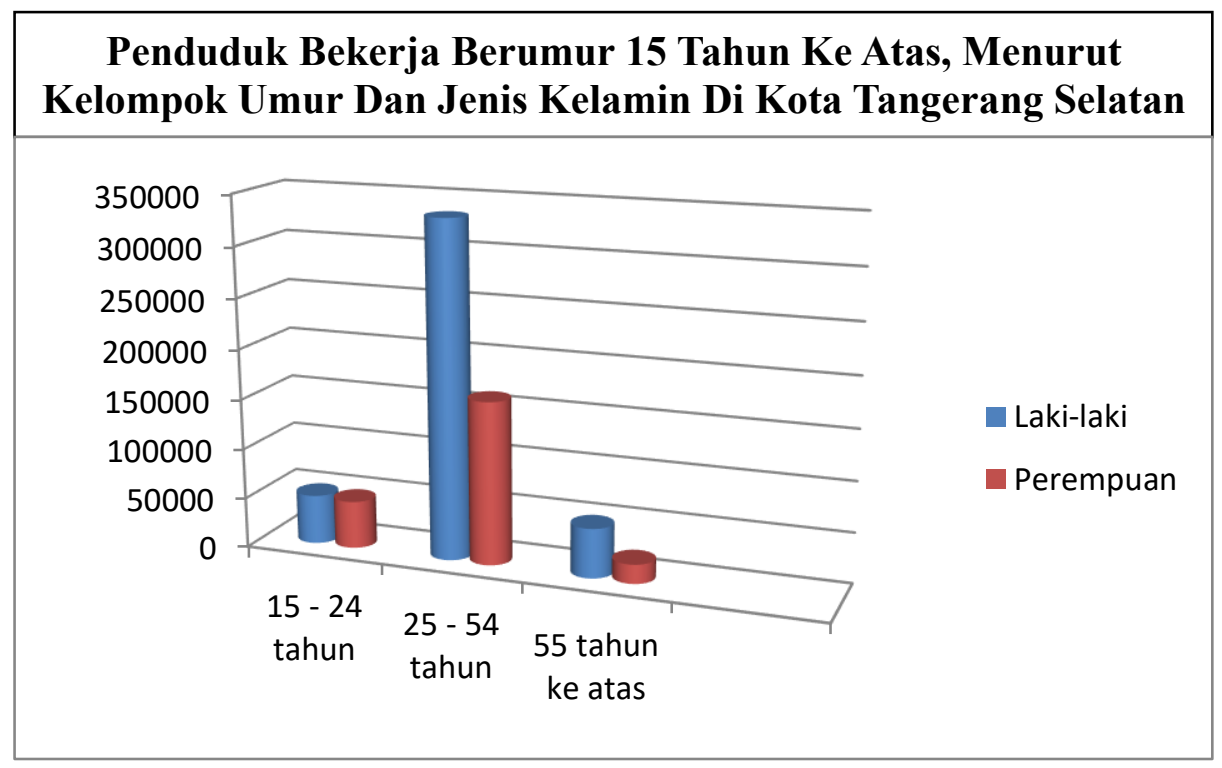

Sumber: BPS (Badan Pusat Statistik) Kota Pamulang Tangerang Selatan 2018

Gambar 1. Data BPS Kota Tangerang Selatan

Dari data tersebut di atas, sudah seharusnya seluruh elemen masyarakat harusnya terus memotivasi para generasi muda untuk dapat berwirausaha, jangan sampai generasi muda kita hanya ingin bekerja dan tidak mau menjadi wirausaha. Dari penelitian yang dilakukan kepada mahasiswa Universitas Trunojoyo, yaitu A.A. Vilathuvahna dan Nugroho (2015), Melakukan penelitian terhadap mahasiswa di Universitas Trunojoyo, di antara hasil penelitiannya ialah "Ditemukan bahwa hanya $17 \%$ mahasiswa memiliki keinginan untuk menjadi wirausahawan setelah lulus, lainnya (83\% mahasiswa) berkeinginan untuk menjadi PNS, dosen, jurnalis dan bekerja di tempat lain." 
Dari penelitian tersebut, harusnya menjadi intropeksi dan evaluasi karena dalam mendirikan usaha haruslah mempunyai bekal ilmu dan keterampilan berwirausaha agar usaha yang dijalankan dapat berjalan dengan baik dan menghasilkan laba yang optimal. Oleh karena itu, "Kompetensi SDM dalam hal pengetahuan, keterampilan, serta keahlian manajerial harus dimiliki oleh pemilik UMKM dan juga setiap individu yang bekerja di UMKM" (Ardiana et al. 2010). Maka termasuk remaja masjid pun perlu ilmu pengetahuan dan keterampilan yang diperlukan dalam mengasah kemampuan wirausahanya dengan mengikuti sebuah penyuluhan atau pelatihan dan berani memulai untuk menjalankan bisnis.

Oleh karena itu, generasi muda harus dibuat terobosan dan kita perlu mempersiapkan remaja sebagai generasi muda yang berkompeten dan mempunyai daya saing tinggi di masyarakat, dalam membekali dan memberikan ilmu pengetahuan dan keterampilan wirausaha kepada remaja masjid dengan tema, "Mewujudkan generasi muda yang unggul di era Globalisasi dengan berbekal ilmu wirausaha yang kreatif, inovatif dan diferensiatif pada remaja masjid Al Hikmah Reni Jaya Pamulang Tangerang Selatan".

\section{METODE PELAKSANAAN KEGIATAN}

Metode Pelaksanaan Pengabdian Masyarakat ini di antaranya : Tahap Pertama yaitu Pemberian ilmu kewirausahaan dan motivasi yang diberikan berupa kisah Sukses beberapa orang yang sukses dalam berwirausaha seperti kisah sukses bapak alm. Bob Sadino, ustadz Yusuf Mansur dan bapak DR. (HC). H. Darsono sebagai pendiri Unpam, hal ini agar remaja sebagai generasi muda dapat mengambil pelajaran yang diberikan oleh orang-orang yang sudah menjalankan usaha dan sukses dalam berwirausaha.

Adapun Prof. Dr. S. Nasution (2015:26) berpendapat mengenai "Ciri-ciri Belajar yang ditinjau berdasarkan sumber yaitu diantaranya memanfaatkan sepenuhnya segala sumber informasi sebagai sumber bagi pelajaran termasuk alatalat audio-visual dan memberi kesempatan untuk merencanakan kegiatan belajar dengan mempertimbangkan sumber-sumber yang tersedia." Dalam pemberian materi kewirausahaan oleh dosen-dosen menggunakan alat bantu berupa infocus agar remaja masjid lebih fokus dalam mengikuti penyuluhan seperti gambar di bawah ini:

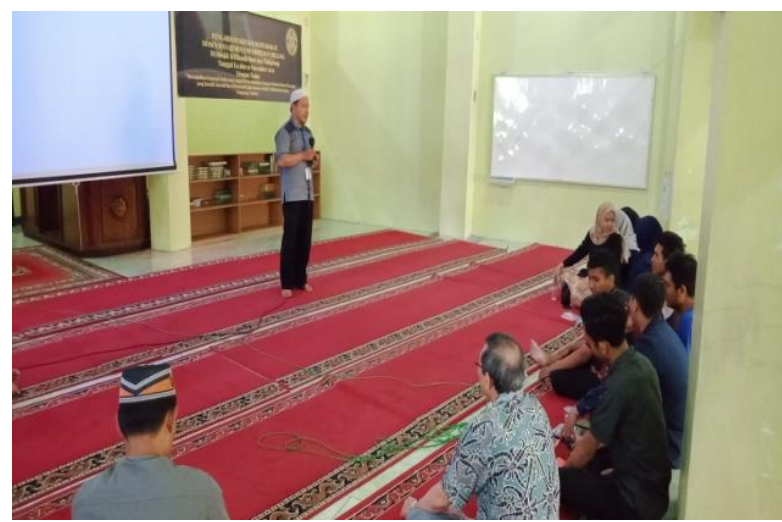



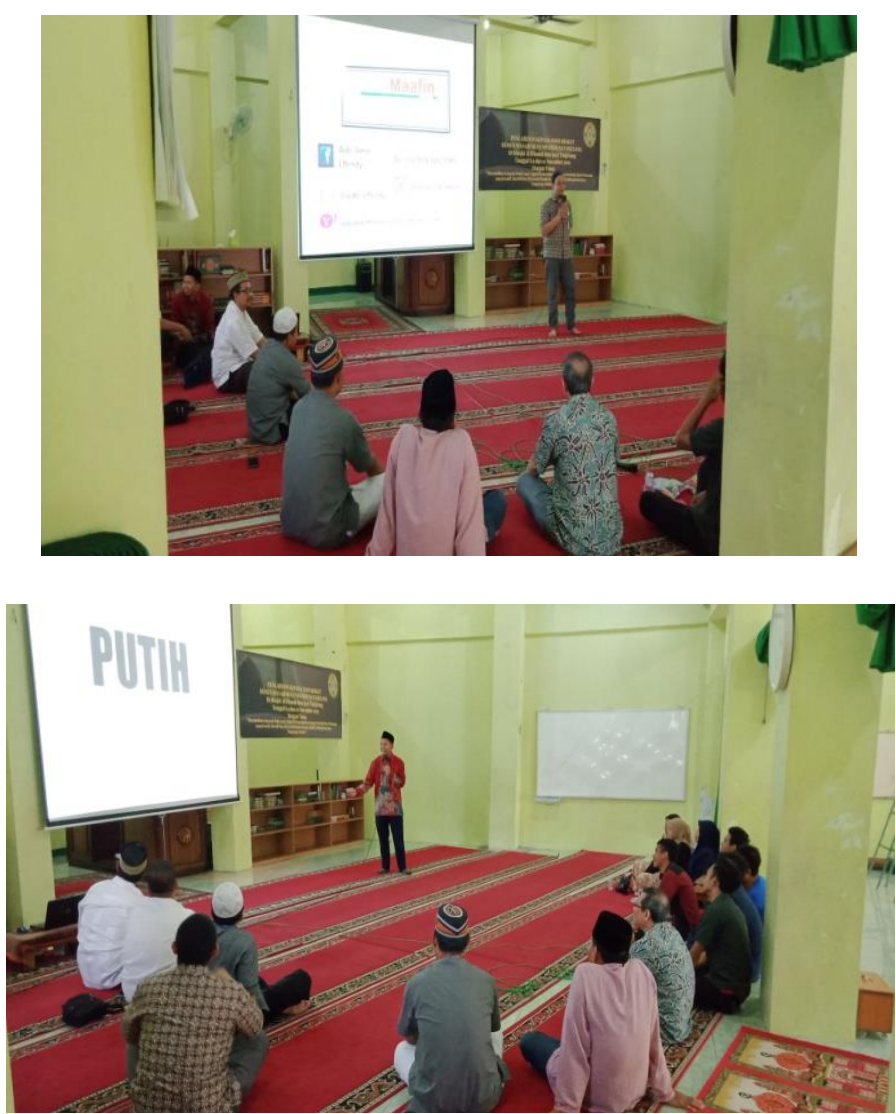

Gambar 2. Tim PKM Dosen Universitas Pamulang Sedang Memberikan Materi

Tahap kedua yaitu : Diskusi, Tanya Jawab dan Bimbingan dalam menjalankan bisnis, yaituu bimbingan bagaimana cara menjual produk dan kemudian dibimbing sampai remaja masjid benar-benar dapat memulai dan menjalankan usahanya.

Tahap ketiga yaitu : Praktek dan simulasi cara dagang dan bahasa dalam menjual produk, sehingga pihak remaja masjid dapat langsung belajar mempraktekkan cara menjual produk dengan bahasa yang baik, mudah dipahami konsumen dan produk yang kita jual agar mudah laku di pasaran.

Kegiatan diadakan di masjid Al Hikmah Reni Jaya Pamulang Tangerang Selatan, terhadap remaja masjid selama 3 hari yaitu pada tanggal 9, 10 dan 17 November 2019.

\section{HASIL DAN PEMBAHASAN}

Hasil dari pemberian materi kewirausahaan oleh dosen Manajemen Universitas Pamulang dan motivasi yang diberikan berupa kisah Sukses beberapa orang yang sukses dalam berwirausaha serta diskusi dan Tanya jawab yang dilakukan saat kegiatan berlangsung dapat berguna bagi para remaja masjid Al Hikmah dalam meningkatkan keterampilan dan keilmuan mengenai 
kewirausahaan, sehingga dapat menjadikan remaja masjid Al Hikmah menjadi lebih termotivasi untuk dapat belajar berwirausha.

Selain pemberian materi dan motivasi, tim PKM juga mengadakan praktek dan simulasi cara dagang dan bahasa dalam menjual produk, karena generasi Muda saat ini sudah sepatutnya mempunyai keilmuan, keterampilan dan wawasan mengenai kewirausahaan, karena produk-produk luar negeri sudah menjamur di masyarakat, sehingga generasi wirausaha muda harus selalu siap bersaing dengan produk luar negeri yang sudah mnguasai produk di dalam negeri.

Hasil pengabdian masyarakat yang diperoleh adalah bertambahnya keilmuan remaja masjid Al Hikmah mengenai kewirausahaan dan dapat menjalankan usaha dengan bekal ilmu dan wawasan mengenai kewirausahaan yang diberikan.

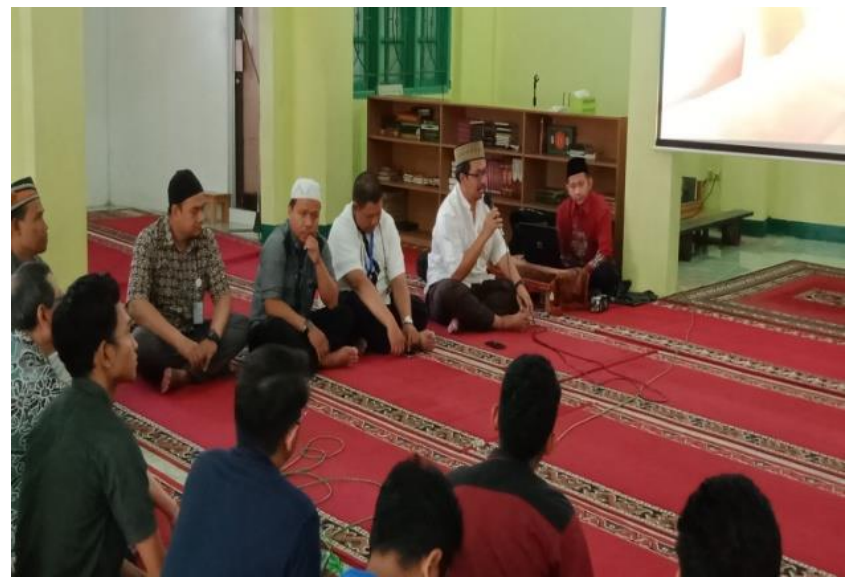

Gambar 3. Pembukaan oleh Tim PKM

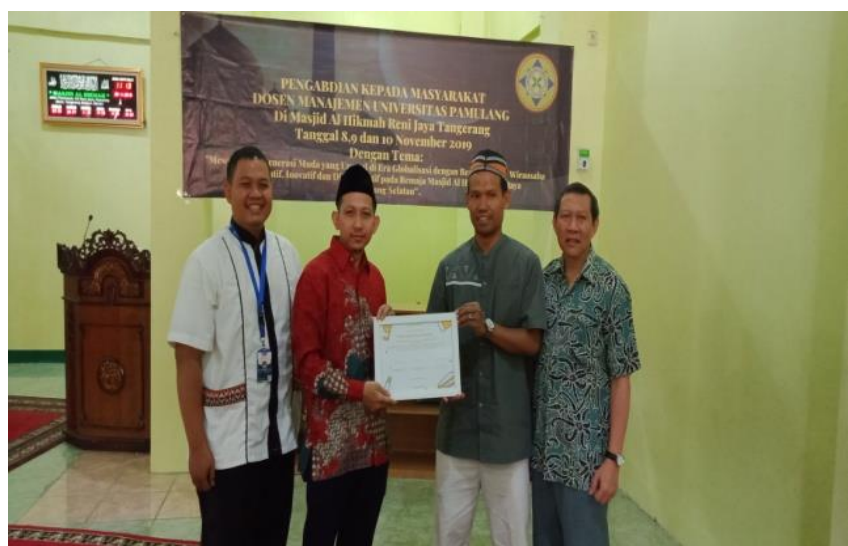

Gambar 4. Pemberian Piagam Penghargaan

Kegiatan pada gambar di atas pembukaan dan doa agar seluruh rangkaian kegiatan PKM dapat berjalan lancar, yang dilanjutkan dengan mengadakan ice breaking sebelum pemberian materi kewirausahaan agar remaja masjid- lebih fokus dalam mengikuti penyuluhan yang dilakukan dosen-dosen Fakultas Ekonomi Universitas Pamulang. 


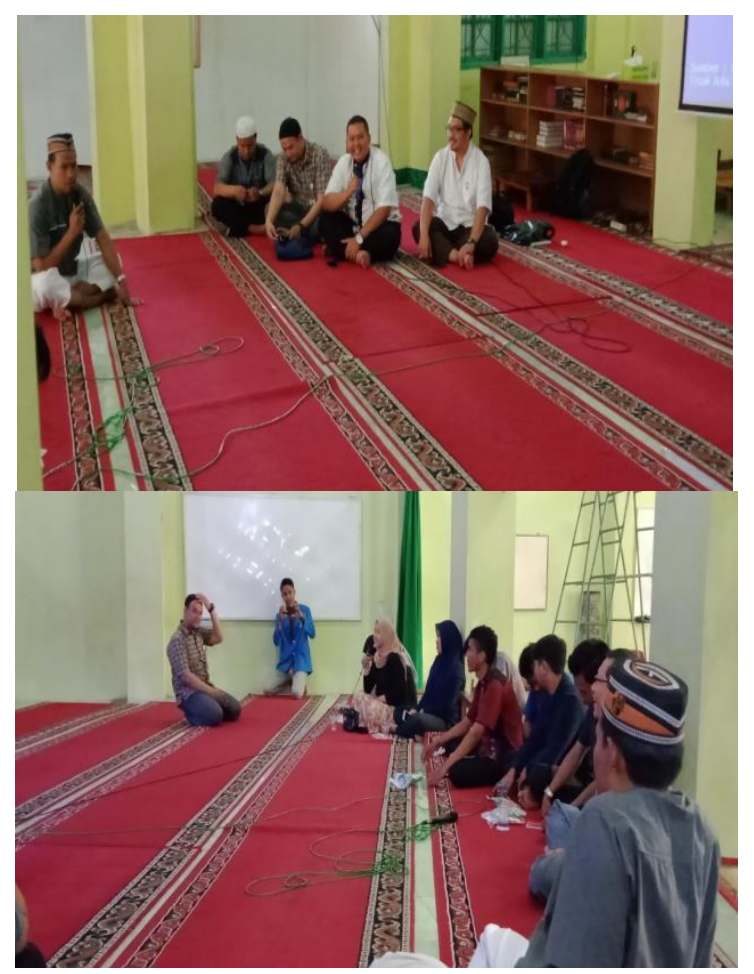

Gambar 5. Sesi Diskusi dan Tanya Jawab bersama remaja masjid Al Hikmah yang bertanya dan menjawab kuis dari Tim PKM Dosen Universitas Pamulang

Adapun gambar di atas yaitu diskusi dan tanya jawab antara remaja masjid $\mathrm{Al}$ Hikmah kepada Tim PKM, kemudian Tim PKM yang merupakan dosen-dosen Unpam menanggapi dan menjawab pertanyaan yang diajukan oleh remaja masjid $\mathrm{Al}$ Hikmah.

\section{KESIMPULAN DAN SARAN}

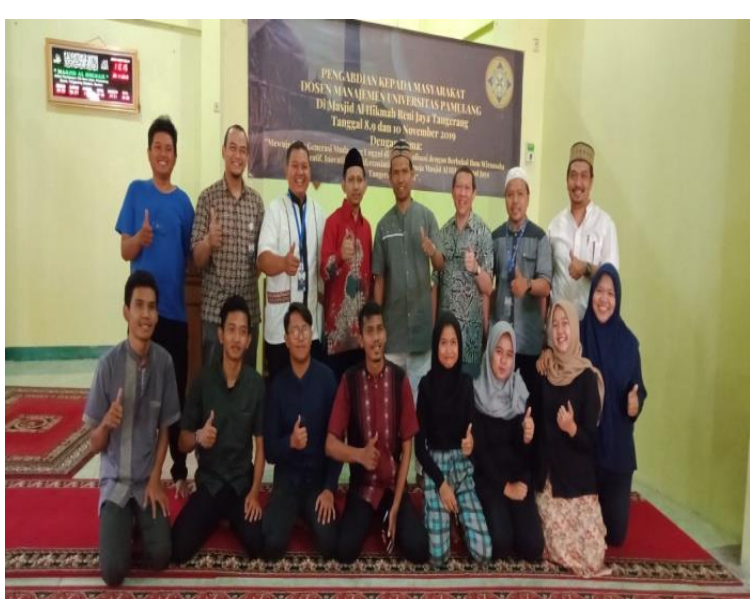

Hasil dari Pelaksanaan kegiatan PKM oleh dosen-dosen Fakultas Ekonomi Universitas Pamulang dapat membuahkan hasil yang positif terlihat dari antusias dan bersemangat dalam mengikuti pemberian materi, tanya jawab dan kuis.

Saran kami bagi remaja masjid Al Hikmah untuk dapat memiliki usaha masing-masing yang dapat berjalan lancar dan sukses usahanya.

Kami berharap kegiatan pengabdian kepada masyarakat di masa yang akan datang dapat lebih terprogram dan terlaksana dengan baik. Semoga kegiatan 
pengabdian masyarakat ini dapat bermanfaat bagi masyarakat, khususnya remaja masjid Al Hikmah.

\section{DAFTAR PUSTAKA}

A Sobarna, S Hambali, S Sutiswo, D Sunarsi. (2020). The influence learning used ABC run exercise on the sprint capabilities. Jurnal Konseling dan Pendidikan 8 (2), 67-71

Ardiana, I.D.K.R., Brahmayanti, L.A. dan Subaedi. 2010. "Kompetensi SDM UKM dan Pengaruhnya Terhadap Kinerja UKM di Surabaya." Jurnal Manajemen dan Kewirausahaan, 12 (1)

BPS (Badan Pusat Statistik) Kota Tangerang Selatan. 2019 https://tangselkota.bps.go.id/publication.html?Publikasi\%5BtahunJudul\%5 $\mathrm{D}=2018 \&$ Publikasi\%5BkataKunci\%5D=\&yt0=Tampilkan, diakses pada Desember 2019

Effendy, A. A., Murtiyoko, H., \& Wicaksono, W. (2019). "Pemberian Motivasi Dalam Membangun Genenerasi Muda Yang Berkompeten Dan Religius Pada Madrasah Aliyah Ummul Qura Pondok Cabe, Pamulang Tangerang Selatan.” Jurnal Pengabdian Dharma Laksana, 2(1), 1-5

Nasution, Prof. Dr. S., 2015. "Berbagai Pendekatan dalam Proses Belajar dan Mengajar", PT Bumi Aksara, Jakarta

Sarwani, S. (2018). Hubungan Antara Perhatian Ibu-Ibu Dalam Menonton Iklan Gizi Di Televisi Dengan Kualitas Perawatan Gizi Di Kecamatan Banjarmasin Selatan Kota Banjarmasin. Metacommunication: Journal of Communication Studies, 2(2).

Sarwani, S., Syamsiah, N. O., \& Dina, F. (2018). Pemanfaatan Perangkat Lunak Akuntansi untuk Menghasilkan Laporan Keuangan pada PT. PNM ULaMM PTPM Pontianak. Moneter-Jurnal Akuntansi dan Keuangan, 5(1), 105-118.

Sarwani, S. (2019). Pengaruh Kinerja Polri Dan Pelayanan Terhadap Kepuasan Masyarakat Pada Sim Satlantas Polres Tanggamus. Jurnal Simplex, 2(2).

Sunarsi, D., \& Asmalah, L. (2018). Pelatihan Manajemen Pengembangan Diri Bagi Penerima Beasiswa RZIS UGM Dan Dompet Shalahuddin Jogjakarta. Jurnal Pengabdian Dharma Laksana, 1(1).

Sunarsi, D., Kusjono, G., \& Nuryana, I. (2019). Pelatihan Manajemen Penguasaan Kelas Dan Pembuatan Bahan Ajar Bagi Tenaga Pengajar Sukarela Taman Belajar Kreatif Mekarsari. Jurnal Pengabdian Dharma Laksana, 2(1), 41-44.

Sunarsi, D., Kustini, E., Lutfi, A. M., Fauzi, R. D., \& Noryani, N. (2019). Penyuluhan Wirausaha Home Industry Untuk Meningkatkan Ekonomi Keluarga Dengan Daur Ulang Barang Bekas. BAKTIMAS: Jurnal Pengabdian pada Masyarakat, 1(4), 188-193.

Vivathuvahna, A.A. dan Nugroho, T.R.D.A. (2015). "Intensi Kewirausahaan Mahasiswa Universitas Trunojoyo Madura.” Jurnal Agriekonomika, 4 (1). 